\title{
○emestáo
}

\section{Museus e justiça de transição no contexto brasileiro: memória e informação na construção de espaços de representação do trauma}

\author{
Felipe Eleutério Hoffman \\ Doutorando; Universidade Federal de Minas Gerais, Belo Horizonte, MG, Brasil; \\ hoffmanfelipe@yahoo.com.br \\ Maria Guiomar da Cunha Frota \\ Doutora; Universidade Federal de Minas Gerais, Belo Horizonte, MG, Brasil; \\ frotaguiomar@yahoo.com.br
}

\begin{abstract}
Resumo: Por todo o globo, acontecimentos como o Holocausto, o Apartheid, o Onze de Setembro, e os períodos ditatoriais na América Latina, têm gerado uma obrigação de se prestar contas ao passado, principalmente através de uma necessidade de marcar a época com a criação de lugares de memória. O surgimento de museus e memoriais que lidam com as memórias da repressão e resistência nos contextos ditatoriais dos países latino americanos do Cone Sul acompanha este contexto global em que se observa a criação de um número crescente de instituições de informação e memória que adotam as causas locais com relação aos direitos humanos como questão principal de sua missão institucional. O presente ensaio objetiva analisar o surgimento de instituições museais em contextos de justiça transicional com foco por sobre a realidade brasileira. São delineados alguns dos aspectos centrais que envolvem o estabelecimento destas instituições, bem como algumas das problemáticas implicadas. Nesta direção, traz um panorama e apresenta algumas destas iniciativas em âmbito nacional. É observado que no que tange o contexto brasileiro, as medidas que caracterizam o campo da justiça transicional possuem estágios diferenciados de implementação em cada uma de suas dimensões e, de maneira geral, diferentes autores reconhecem que muitas medidas são consideradas tardias em relação a outros países da América Latina.
\end{abstract}

Palavras-chave: Memória. Informação. Museu. Justiça de Transição. Brasil.

\section{Introdução}

Entre as diversas reflexões sobre a cidade, ganham destaque, desde o final do século passado, os estudos que abordam a relação entre estes espaços e a temática da memória. É evidenciada uma valorização do passado na paisagem e nas chamadas instituições de informação e de memória, tradicionalmente nos museus, arquivos e bibliotecas. Conforme apontam alguns estudiosos, temos, na 
contemporaneidade, uma verdadeira onda memorialística em que se nota um crescimento na produção e difusão de diferentes tipos de narrativas de cunho memorial ou testemunhal, bem como uma crescente proliferação de diversas instituições e lugares de memória.

Em meio a esta profusão de práticas e lugares memoriais, destaca-se como de fundamental interesse para o presente ensaio, o surgimento, principalmente a partir de um discurso patrimonial, de novos espaços vinculados a memórias traumáticas, a dor e ao sofrimento. Este boom da memória, como denominam Huyssen (2000) e Winter (2006), no que se refere à patrimonialização do trauma, tem, talvez, como seu exemplar mais significativo, a questão do Holocausto e a criação de espaços de memória relacionados. $\mathrm{Na}$ mesma direção outros acontecimentos tem despertado uma série de memórias e narrativas.

Por todo o globo, acontecimentos como o Holocausto, o Apartheid, o Onze de Setembro, e os períodos ditatoriais na América Latina, têm gerado uma obrigação de se prestar contas ao passado, principalmente através de uma necessidade de marcar a época com a criação de lugares de memória. Embora diversificadas, estas instituições comumente constituem-se com o intuito de que as gerações futuras conheçam e não permitam que violações com o mesmo cunho voltem a ocorrer, além de compor um dos eixos estruturantes da reparação moral às vítimas da violência de Estado outrora sofrida (KREUZ, 2014).

Geralmente, tais lugares de memória surgem a partir de movimentos sociais e políticos em defesa de suas memórias ou das memórias as quais se posicionem como guardiões. Instituem-se para evitar o esquecimento, através da ação do Estado, muitas vezes, em resposta às reivindicações das comunidades que defendem esses lugares como seus. No entanto, não é rara a ocorrência de desvios nestes processos. A apropriação de iniciativas exitosas e organizadas pelo Estado, com o passar do tempo, por exemplo, pode ocasionar algumas mudanças significativas nos rumos e significados destes lugares. Valorização, apropriação, usos turísticos e desapropriação são apenas algumas das consequências que podem decorrer destas ações. 
Outra questão para se pensar estes processos na contemporaneidade é a constatação de que estas memórias, ao serem "patrimonializadas", tendem a resultar na afirmação de uma narrativa única a respeito dos acontecimentos que referenciam, em detrimento de uma multivocalidade. Vozes alternativas sobre o passado são reprimidas. Inserem-se, então, na disputa entre o que deve ou não ser rememorado, podendo resultar, por meio de sua mercantilização, em um processo de banalização da memória.

A partir destes apontamentos, observa-se que tanto agentes do Estado como os membros da sociedade civil se colocam, na construção de tais espaços, em um campo de disputas, de desejos e direito a memória. Onde se torna crucial entender que a circulação destas memórias pode ser tanto benéfica quanto destrutiva para as comunidades que as experienciaram em seus contextos específicos.

As representações de traumas históricos, portanto, propõem grandes desafios teóricos, éticos e políticos, que se refletem nas ações que têm como objetivo uma prestação de contas com o passado, com vistas à reparação ou ressarcimento às vitimas da violência de Estado e violações dos direitos humanos. Tais acontecimentos não têm como objetivo atingir apenas as comunidades diretamente afetadas, mas se reconhece uma dimensão ampliada para os acontecimentos traumáticos. A “[...] reparação não é uma tarefa individual e, também, não pode ser individualizada. A sociedade como um todo foi vítima das estratégias de implantação do terror, cujas ameaças concretizaram-se para algumas pessoas [...]” (BAUER, 2014, p. 340).

Se a sociedade não reconhecer a realidade do dano e a necessidade moral de uma reparação, este se manterá reduzido ao universo privado das vítimas ou das famílias e grupos afetados e poderá, nesta direção, aprofundar seus efeitos traumáticos. O que, por sua vez, pode gerar uma marginalização social e política das vítimas, com consequências danosas para o tecido social local. A instauração ativa de processos por violações dos direitos humanos nos tribunais também depende da força dos discursos da memória na esfera pública, em suas mais diferentes mídias e formas de representação, seja nos filmes, jornalismo, literatura, educação ou nas artes. 
É dentro deste contexto que estes museus, memoriais e monumentos são construídos, com o objetivo de "abrigar" estas memórias para que as gerações futuras conheçam e não permitam que violações com o mesmo cunho voltem a ocorrer. Ao mesmo tempo, observa-se, dentro das linhas de atuação destas instituições, a presença um horizonte de criação de uma cultura democrática. Tornam-se espaços de representação que permitem o entrelaçamento entre as esferas privadas e públicas destas memórias e compõem um dos eixos estruturantes da reparação moral às vítimas da violência de Estado ou violações dos direitos humanos sofridos pelos grupos sociais. Encontram-se completamente imersas nas discussões que envolvem a memória e a informação na sociedade contemporânea.

\section{Justiça de Transição, Museus e o contexto do Cone Sul}

O surgimento de museus e memoriais que lidam com as memórias da repressão e resistência nos contextos ditatoriais dos países do Cone Sul acompanha uma tendência global em que se observa a criação de um número crescente de instituições de informação e memória que adotam as causas locais, com relação aos direitos humanos, como questão principal de sua missão institucional ${ }^{1}$.

Em uma conjuntura contemporânea em que se observa a possibilidade do emprego de meios "técnicos" para dar opacidade à informação, estes museus, em uma perspectiva de transparência, na condição de locais de informação e comunicação, possibilitam que memórias antes legadas à clandestinidade ascendam ao espaço público de forma a permitir um acesso à informação:

[...] na sociedade da informação assegurasse cada vez mais a retirada da clandestinidade dos conteúdos das memórias ligadas ao período da ditadura, ou não, como resultado de uma conquista legítima, um direito à vida, à liberdade. $\mathrm{O}$ direito à informação traz consigo o sopro da democracia, a chave de tempos melhores, mais indagativos.(CASTRO, 2002, p. 26).

A proliferação de ditaduras nestes países, nas décadas de 1960 e 1970, foi, notadamente, caracterizada por contextos de repressão, marcados por uma conjuntura de censura, mortes, torturas e desaparecimentos ${ }^{2}$ e, ao mesmo tempo, por mobilizações de resistência, produzindo situações de exílio e o surgimento de grupos de reação e conflito com os regimes. 
As diferentes memórias sobre estes períodos revelam as mais diversas instâncias de disputas no estabelecimento de um processo de rememoração e de construção das variadas narrativas, principalmente no que diz respeito à implantação de uma política de memória sobre os acontecimentos. Nestes contextos, a criação destes espaços de memória nos diferentes países do Cone Sul enfrenta enormes desafios, pois ressalta o sentido da patrimonialização destas memórias como forma de luta social. A partir da perspectiva de Ferraz (2007):

Essa preservação deve levar em consideração que o significado da memória política é o de luta social. Consagrar o patrimônio que tenha como função apenas ressaltar a presença do Estado opressor e negligenciar as experiências daqueles que se opunham ao regime ou ofuscar o seu poder político naquela época e hoje, é acentuar apenas o lado frio da memória, desconectá-la de sua representatividade, de sua luta política e das relações sociais que se estabeleceram. É também colaborar para a perpetuação do trauma de centenas de indivíduos [...] (FERRAZ, 2007, p. 55).

Desta forma, muitas destas instituições são criadas, a partir da perspectiva de um dever de memória em contextos de justiça de transição, geralmente por governos ou grupos responsáveis por esta transição após o período em que se efetivou a situação de opressão ou violação dos direitos. Frequentemente, as Comissões da $\operatorname{Verdade}^{3}$ criadas nos diversos países após períodos de abuso de poder recomendam, como forma de reparação simbólica às vítimas do abuso ou da violência de Estado, que se materialize um memorial. Embora possam estar ligadas a questões e lutas relacionadas a contextos regionais, estes memoriais, que em sua maioria assumem a forma de museus, permitem uma experiência compartilhada de identificação com os grupos e suas memórias. Em sua quase totalidade, a mensagem central defendida por estas instituições é a de que a lembrança destes acontecimentos funcione como catalisadoras de um movimento que impeça a repetição de situações semelhantes. Advindo daí a ideia do "Never again", "Nunca más", "Nunca Mais". Nota-se o papel fundamental da ideia de justiça de transição no estabelecimento destas instituições.

O conceito de justiça de transição, também encontrado na literatura como justiça transicional, é relativamente novo nas ciências sociais. Suas raízes 
remontam ao contexto Pós-Segunda Guerra Mundial e o mesmo passa a ganhar maior relevância a partir dos anos de 1980, com a incorporação de uma filosofia moderna de universalidade da humanidade e de dignidade humana nos sistemas jurídicos e nas estruturas políticas e sociais. É caracterizada como um conjunto de mecanismos para lidar com o legado de violência de Estados autoritários, ou que sejam incapazes de preservar a integridade de seus cidadãos (ABRÃO; DIÈNE, 2015; REATEGUI, 2011).

Tem como objetivos centrais reconhecer as violações de direitos e instaurar ferramentas que promovam uma justiça de longo prazo e proporcionem a valorização dos direitos humanos como um princípio fundamental de uma sociedade que emerge de uma situação de conflito.

Desta forma, a justiça de transição pode ser definida, de maneira ampla, como o processo que tem como propósito:

[...] o (re)estabelecimento do Estado de direito, o reconhecimento das violações dos direitos humanos -suas vítimas e seus autores- e a promoção das possibilidades de aprofundamento democrático pela justiça, verdade, reparação, memória e reforma das instituições. (ABRÃO; GENRO, 2012, p. 33).

Ela se desenvolve como um esforço para a construção de uma paz que seja sustentável após períodos de conflitos, violações sistemáticas de direitos humanos e situações de violência em massa. Apresenta, como características fundamentais, quatro dimensões: reparação às vítimas; busca da verdade e construção da memória; regularização da justiça e restabelecimento da igualdade perante a lei; e a reforma das instituições perpetradoras de violações contra os direitos humanos (ABRÃO, 2012).

Ao considerar estas quatro dimensões, nota-se que a implantação de museus e memoriais, dentro do contexto de justiça de transição, atende, essencialmente, à um duplo aspecto, pois, além de funcionarem como políticas de reparação individual e coletiva, moral e simbólica, possuem, ao mesmo tempo, uma dimensão clara de formação de memória.

No que diz respeito à dimensão prática, os procedimentos de justiça transicional podem ser classificados em cinco tipos: 
[...] a) apuração e responsabilização dos crimes ocorridos nas ditaduras ou conflitos civis para o (re)estabelecimento do estado de direito; [...] b) criação das comissões de verdade, que são os instrumentos de investigação e informação sobre os abusos chaves de períodos do passado caracterizados pela censura e pela baixa transparência informacional [...], c) programas e comissões de reparação às vítimas, [...], d) reformas institucionais dos sistemas de segurança para adequá-los ao respeito à cidadania e a integridade social, [...] e) políticas públicas de memória com práticas institucionais que implementem memoriais e outros espaços capazes de resignificar a história do país.(ABRÃO; GENRO, 2012, p. 3443).

Nesta direção, torna-se claro que a implantação destes espaços dentro de processos de justiça de transição se constitui como uma prática que contribui no estabelecimento de políticas para a memória enquanto um mecanismo de fortalecimento da democracia. Estes memoriais materializam a identidade do processo e se constituem como poderosas ferramentas de compartilhamento e conscientização sobre as diferentes memórias e narrativas dentro dos diversos contextos de repressão e resistência.

Deve-se observar que o objetivo destes espaços não deve ser de estabelecimento ou imposição de uma história ou narrativa oficial, mas sim o de demonstrar os diferentes conflitos presentes na implementação destes lugares. Por vezes, o processo pelo qual se concretiza um memorial pode ser tão ou mais importante do que o resultado em si. Conforme estabelece Jelin, a natureza destes espaços é necessariamente conflituosa e processual:

\begin{abstract}
A controvérsia e o conflito de interpretações com a versão do sentido do passado imposta ou negociada pelos vencedores não necessariamente desaparecem uma vez construído o memorial, o museu, o monumento. A passagem do tempo histórico, político e cultural necessariamente implica novos processos de significação do passado, com novas interpretações. E então surgem revisões, mudanças de narrativas e novos conflitos [...] (JELIN, 2002, p. 5657 , tradução nossa ${ }^{4}$.
\end{abstract}

Embora seja possível mapear estratégias comuns, os processos de justiça de transição em todo mundo adquirem diferentes contornos, da mesma forma, na América Latina os procedimentos de justiça transicional têm adquirido formas e percursos distintos em cada país e essas distinções estão diretamente correlacionadas aos processos transicionais dos regimes ditatoriais para os democráticos (FROTA, 2017). 
A memória dos regimes ditatoriais e seu contexto de repressão e resistência bem como a prestação de contas com o passado, perpassa por questões complexas que reverberam da articulação e reivindicação pela construção de espaços de memória, chegando ao contexto mais amplo de justiça transicional.

As transições no Cone Sul foram distintas e singulares e as memórias dos conflitos sociais prévios à instauração ditatorial, assim como a crueldade e a imediatez das violações de direitos humanos durante as mesmas, criaram cenários para manifestação de confrontos, no marco de um difícil intento de gerar consensos entre os diversos atores políticos. As vozes censuradas e proibidas começaram a fazer-se ouvir, mas as vozes autoritárias não necessariamente desapareceram do debate público. [...]. Eram atores e forças políticas internas [...] que tinham de conviver no marco das novas regras do funcionamento democrático. (JELIN, 2002, p.47, tradução nossa $\left.{ }^{5}\right)$.

\section{Justiça de Transição no contexto brasileiro}

No que tange o contexto brasileiro, as medidas que caracterizam o campo da justiça transicional possuem estágios diferenciados de implementação em cada uma de suas dimensões e, de maneira geral, diferentes autores reconhecem que muitas medidas são consideradas tardias em relação a outros países da América Latina $^{6}$. Via de regra, a transição brasileira é caracterizada como um processo lento e gradual, marcado por medidas pontuais liberalizantes que começam a ser implementadas a partir da segunda metade da década de 1970, com medidas como eleições estaduais diretas, a promulgação da Lei de Anistia (BRASIL, 1979), entre outras, que vão se estender pelo período de redemocratização até chegarmos aos dias atuais (ABRÃO, 2012; FROTA, 2017).

Dentro desta perspectiva, temos ainda poucas instituições museais dedicadas à preservação de memórias ligadas a acontecimentos traumáticos ou a promoção dos direitos humanos. Parte disto está ligado ao fato de que a experiência brasileira mais traumática nos últimos anos, o período da ditadura civil-militar que se deu no país entre os anos de 1964-1985, apenas recentemente vem ganhando debates e discussões ampliadas.

Muito se deve, também, à Lei da Anistia, promulgada em 1979, que, ao mesmo tempo em que se constitui como passo importante a partir da 
possibilidade de retorno ao país ou, ainda, da retirada da clandestinidade de centenas de ex-perseguidos políticos, provocou, nas palavras de Ricoeur, um “esquecimento comandado" (RICOEUR, 2007). Para Ricoeur (2007), a anistia representa uma das formas institucionais de esquecimento. Muitas das democracias modernas fazem uso deste gênero de esquecimento por imposições e razões que visam à manutenção de uma paz social como maneira de colocar fim a graves desordens políticas que afetam a paz civil. Configura-se então como um "não se esquecer, de esquecer". No entanto, para o autor, a prática da anistia apresenta, como uma falha, o apagamento da memória oficial de exemplos de crimes cometidos, cuja lembrança pode atuar de maneira a proteger o futuro das faltas do passado (RICOEUR, 2007). Ao privar a opinião pública dos benefícios do dissenso, a anistia pode condenar as memórias concorrentes a uma vida clandestina e subterrânea, se aproxima, portanto, de uma prática da amnésia (RICOEUR, 2007).

Nesta medida, tendo em vista que a interpretação dada à lei naquele momento foi a de que era um caminho de "mão dupla", foram anistiados, perseguidos e perseguidores. Ao controlar a transição política, os setores ligados às forças armadas não permitiram, num primeiro momento, que as instituições e a população brasileira em geral se confrontassem de maneira direta com o passado de arbitrariedades e abusos cometidos.

No entanto, se por um lado se produziu uma instância de não responsabilização criminal dos perpetradores de graves violações aos direitos humanos durante a ditadura civil-militar, houveram avanços no que tange às medidas de reparação às vítimas e à garantia de direitos:

[...] no caso brasileiro, como se pode verificar, as medidas de abrangência temporal retroativa, como a investigação de crimes passados, enfrentaram de forma mais marcada as restrições políticas do antigo regime por atingirem diretamente a seus membros, enquanto as medidas de reparação as vítimas e garantia de direitos futuros se mostraram mais eficientes em romper o cerco político, na medida em que não afetavam de forma direta os membros do antigo status quo e as limitações que impuseram à transição quando ainda estavam no poder. (ABRÃO, 2012, p. 65).

É importante ressaltar que os círculos de familiares de mortos e desaparecidos, organizações em defesa dos direitos humanos e alguns 
pesquisadores e grupos de pesquisa sempre promoveram instâncias e lutas para o reconhecimento das atrocidades do período. Apenas recentemente tivemos as condições de abertura política para promover uma discussão ampliada sobre a memória deste acontecimento. No entanto, a Comissão Nacional da Verdade $(\mathrm{CNV})^{7}$, instituída em 2012, encerrou seus trabalhos no final de 2014. Entre as atribuições da Comissão, encontrava-se “[...] identificar e tornar públicos as estruturas, os locais, as instituições e as circunstâncias relacionados à prática de violações de direitos humanos [...]" (BRASIL, 2011, doc. não paginado). Espera-se que, potencialmente, alguns destes locais possam se tornar lugares de memória, que tenham como objetivo preservar as memórias deste período.

A recente crise político-financeira, bem como as ondas de manifestações e protestos dos últimos anos, são fortes indícios de que as memórias sobre nossa história recente precisam ser ainda discutidas. Não raras foram as demonstrações de manifestantes que se posicionam a favor de uma nova intervenção militar, enquanto outros cobravam uma revisão dos acontecimentos deste período, com o desejo de apuração de culpas e punição a torturadores e colaboradores do regime. Estes acontecimentos talvez demonstrem a ineficácia do instrumento da Anistia para lidar com as memórias deste período.

Até o momento, mesmo com todos os avanços, o governo brasileiro tem se caracterizado por uma postura de tratamento apaziguado sobre a memória da Ditadura civil-militar. Outros acontecimentos traumáticos e episódios sistemáticos de violação de direitos humanos presentes na história do país têm sido completamente negligenciados.

\section{Lugares de memória, lugares de resistência}

Neste contexto transicional é que se desenvolvem, no Brasil, projetos de implantação de instituições museais que tem como missão institucional preservar a memória de acontecimentos que se relacionam a episódios de dor, sofrimento e violações de direitos. Embora apresentem diferentes formas de articulação, estes museus ou centros de memória têm, prioritariamente, se dedicado à rememoração de episódios relacionados à ditadura civil-militar que foi instaurada no país a partir do golpe civil-militar em abril de 1964. As 
memórias de repressão, resistência, censura, tortura e desaparecimentos, que marcaram este período, têm emergido desde a abertura democrática, que se efetiva de maneira gradual no país a partir de 1985, com o fim do regime.

De maneira contrastante com os demais países da América do Sul, no Brasil ainda são poucas as iniciativas que primam por construir uma memória pública sobre estes acontecimentos através da instituição de museus e memoriais. Este movimento têm se intensificado na atualidade, fruto de um contexto político que, ainda que seja conturbado, é favorável a estas discussões, principalmente com a fundação da Comissão Nacional da Verdade (CNV), criada pela Lei 12.528/2011 (BRASIL, 2011) e instituída em 16 de maio de 2012.

Verifica-se, dentro das propostas engendradas, a recorrência de uma reivindicação de antigos espaços relacionados às práticas de opressão ou de resistência a este regime como parte fundamental dos projetos. Seja como sede para implantação destes museus ou como espaços, que, por sua materialidade, são utilizados dentro da narrativa museal como potencial recurso museográfico.

O relatório final da Comissão foi divulgado no ano de 2015 e, no capítulo 15 de seu primeiro volume, apresenta um mapeamento das instituições e locais associados a graves violações de direitos humanos. Identificar e tornar públicos as estruturas, os locais, as instituições e as circunstâncias relacionados à prática de violações de direitos humanos durante o período investigado era um dos objetivos legalmente definidos para a $\mathrm{CNV}$ - presente no artigo $3^{\circ}$, inciso III, da Lei no 15.258/2011 (BRASIL, 2011).

Alguns destes locais encontram-se documentados de maneira ampla, com fotografias, mapas, plantas e representações que são cotejados e analisados em consonância com depoimentos de especialistas, pesquisadores e sobreviventes. Ao todo, foram identificados pela CNV 229 locais que são apresentados em uma divisão por estados no referido relatório.

Ainda, no que diz respeito à preservação dos lugares de memória, o relatório da Comissão evidencia, no final de seu primeiro volume, uma série de recomendações e apresenta, entre elas, a recomendação de número 28 que trata da preservação da memória das graves violações de direitos humanos: 
[...] Devem ser adotadas medidas para preservação da memória das graves violações de direitos humanos ocorridas no período investigado pela $\mathrm{CNV}$ e, principalmente, da memória de todas as pessoas que foram vítimas dessas violações. Essas medidas devem ter por objetivo, entre outros:

a) preservar, restaurar e promover o tombamento ou a criação de marcas de memória em imóveis urbanos ou rurais onde ocorreram graves violações de direitos humanos;

b) instituir e instalar, em Brasília, um Museu da Memória (BRASIL, 2014, p. 974).

Associada à identificação dos locais relacionados aos contextos de repressão e violações de direitos humanos, a recomendação feita pela CNV expressa, de forma direta, o desejo de que sejam implementados memoriais que se tornem capazes de ressignificar a história do país, por meio da preservação da memória destes acontecimentos, que, de forma sugestiva, pode se dar através da reconversão destes locais em espaços de representação destas memórias.

Pelo valor histórico e político que apresentam, alguns destes lugares acabam por ser selecionados como lugares que merecem uma proteção. Considerados como locais de preservação a partir da identificação de sua materialidade, sua relação física com os episódios de violação de direitos humanos, torna-se um elemento necessário para dar sentido aos acontecimentos. A cada uma destas construções, por suas especificidades, podem ser elencadas diferentes políticas e instrumentos para preservação. Uma destas possibilidades pode ser a efetivação do tombamento (ou outro instrumento similar) da edificação. Outra possibilidade que se apresenta a estes lugares é a efetivação de um processo de musealização destes locais, o que algumas vezes pode incluir a instalação de um museu na edificação.

É nesta medida que uma diversidade de instituições museais ligadas à promoção dos direitos humanos e a preservação da memória de episódios de violação de direitos são criadas. Ao ocupar a edificação que teve como palco o desenrolar dos acontecimentos traumáticos, tais edificações são potencializadas como lugares de memória. O edifício e sua espacialidade se transformam em uma peça fundamental do acervo da instituição, podendo ser utilizado como espaço museográfico que se constitui ao mesmo tempo, a partir de seu caráter documental, em um testemunho. No entanto, muitos destes locais podem se encontrar em mal estado de conservação, devido ao abandono, ou tentativa 
deliberada de apagar possíveis provas ou rastros dos acontecimentos (JELIN, 2002).

Mas cabe lembrar que não somente os locais onde ocorreram torturas ou violências, de maneira explícita ou clandestina, podem ser convertidos em instituições museais. Observa-se uma gama de instituições museológicas que também abordam a memória de acontecimentos traumáticos, mas a partir da preservação de locais onde ocorreram ações de resistência a estas violações de direitos humanos e, até mesmo, locais sem uma relação direta com estas memórias a priori.

Uma das mais conhecidas experiências de adaptação de antigos locais relacionados à ditadura civil-militar brasileira, para uma função museal, é o Memorial da Resistência na cidade de São Paulo. Sediado em parte do prédio que abrigou o Departamento Estadual de Ordem Política e Social (Deops/SP) nos anos de 1939 a 1943. Foi o primeiro centro de detenção, tortura e assassinatos no Brasil a ser tombado em 1999 e, posteriormente, musealizado em 2008. A instalação deste museu não ocorreu sem conflitos e tentativas do governo do Estado de São Paulo de impor políticas de esquecimento (SOUSA, 2014).

A edificação abrigava algumas celas onde se encontravam diversas inscrições de pessoas presas durante o regime militar. No entanto, tais inscrições foram apagadas numa das tentativas de revitalização urbana da região com vistas a instalar no local um "Memorial da Liberdade". O projeto foi amplamente contestado, o que resultou em seu abandono. Diante das pressões políticas (especialmente do Fórum dos Ex-Presos e Perseguidos Políticos) contra o falseamento da história que era o "Memorial da Liberdade", em janeiro de 2009, o espaço foi inaugurado com nova proposta. Desta vez como "Memorial da Resistência". Numa das estratégias museográficas utilizadas pela instituição, alguns ex-presos refizeram parte das inscrições nas paredes das celas, como maneira de marcar simbolicamente o espaço e (re)criar o espaço das celas como ambiente museográfico (SOUSA, 2014).

Outro exemplar de espaço museal já implantado no país, o Memorial dos Direitos Humanos do Mercosul (MDHM), localizado na cidade de Porto 
Alegre, tem como missão preservar memórias que corporifiquem as violações aos direitos humanos originadas pela Operação Condor - a coordenação dos aparatos repressivos das ditaduras do Cone $\mathrm{Sul}$ - alicerçado em um projeto que alia documentação histórica e produção artística.

Idealizada em 2011, durante uma reunião de autoridades em Direitos Humanos do MERCOSUL ocorrida em Montevidéu, a instituição ocupa uma edificação construída em 1914 que abrigava a antiga sede dos Correios e Telégrafos e que, embora seja uma referência patrimonial para a cidade, não apresenta relação direta com os acontecimentos que referencia. Inaugurado em 2014, por ocasião dos 50 anos do golpe civil-militar, o MDHM aborda questões mais amplas ligadas à promoção dos direitos humanos, procurando relacionar experiências históricas com as problemáticas contemporâneas e o direito de minorias.

Outro Memorial da Resistência pode ser encontrado no país, desta vez na cidade de Fortaleza. Idealizado pela Secretaria de Cultura do município em parceria com grupos atuantes na defesa dos direitos humanos, o Memorial da Resistência de Fortaleza se constituí em um espaço para a (re)construção da memória dos cearenses que lutaram contra a ditadura civil-militar no Brasil. Inaugurada em 2012, a instituição ocupa o antigo prédio da Polícia Federal. No espaço, é possível conhecer duas antigas celas e uma solitária utilizadas no período da repressão, além do acervo composto por artefatos e documentos advindos do Arquivo Público do Ceará e do Museu da Imagem e do Som.

Experiências em diferentes fases de implantação podem ser mapeadas por todo país, algumas delas em fase de obras e adaptação como o Memorial da Luta pela Justiça em São Paulo, que visa resgatar a memória dos tribunais de exceção durante a ditadura, onde foram condenados, muitas vezes em julgamentos ilegítimos, pessoas e militantes que enfrentaram o regime. $\mathrm{O}$ memorial visa também se constituir em um local de homenagem aos advogados que lutaram em favor dos Direitos Humanos, em especial àqueles que defenderam perseguidos políticos das ditaduras de 1937-1945 e 1964-1985, e será instalado no edifício da antiga Auditoria Militar.

Outro projeto atualmente em implantação tem como proposta abrigar 
arquivos históricos sobre o período da ditadura civil-militar implantada no Brasil entre os anos de 1964-1986, de forma a trabalhar com as memórias deste período a partir da perspectiva dos perseguidos políticos. Trata-se do Memorial da Anistia Política do Brasil em Belo Horizonte.

O museu se instalará em edificação localizada na região sul da capital mineira, onde era localizada uma escola-laboratório, que se constituía como espaço para formação não só de alunos, mas também dos futuros docentes da instituição, o que lhe rendeu a alcunha pela qual é conhecida ainda hoje, "coleginho". Sua escolha como local para implantação de uma instituição que visa discutir as recordações sobre o período da Ditadura civil-militar no Brasil se dá devido a seu forte simbolismo como espaço que presenciou um dos acontecimentos considerados como um dos capítulos marcantes na trajetória de resistência política ao regime militar na cidade, da qual a UFMG, e, consequentemente, suas instalações, se constituem como um dos principais redutos de resistência.

O espaço museal do Memorial da Anistia ainda não foi inaugurado. No entanto, a instituição já tem executado e apoiado ações, independente de sua existência como espaço físico. Por enquanto, suas edificações permanecem em obras, sem uma previsão oficial para sua inauguração, e a instituição já se envolve em polêmicas relativas ao atraso e paralisação das obras, além de denúncias de desvios de verbas.

Ainda na cidade de Belo Horizonte, outra iniciativa existia, até então, em forma de lei, mas não possuía previsão de implantação. O Memorial dos Direitos Humanos de Minas Gerais, que se origina a partir de uma vontade de memória que se materializou por meio de uma demanda social através da Lei Estadual 13.448 de 2000 (MINAS GERAIS, 2000), legislação que regula a criação da instituição (NORA, 1993). Embora se destaque como projeto precursor, as idas e vindas do projeto de implantação deste memorial, que ocupará a edificação do antigo Departamento de Ordem Política e Social (DOPS) de Belo Horizonte, são representativas das disputas no campo da memória. Elas dão testemunho do quanto estas iniciativas e instituições estão suscetíveis às mudanças e inclinações políticas. 
Em abril de 2018, o projeto recebe novo fôlego quando a gestão estadual anuncia a implantação do agora batizado Memorial dos Direitos Humanos Casa da Liberdade. Em sua cerimônia oficial, o espaço, conforme apresentado por seus idealizadores, se compromete a ser não somente um local para preservação e divulgação das memórias sobre episódios de violações de direitos no país, mas também uma instituição de resistência na luta pelos valores democráticos.

Assim como o Memorial dos Direitos Humanos, diversas outras experiências sobrevivem no desejo e na luta pelo direito a memória e a verdade de diferentes pessoas, coletivos e grupos sociais. Caso das sucessivas reivindicações e manifestações a favor da criação de centros de memória na antiga edificação do DOPS do Rio de Janeiro e na conhecida "Casa da Morte", em Petrópolis, ambas notórios centros de repressão e tortura do Regime. Em todas as iniciativas, entre os traços comuns, destaca-se a trajetória conturbada de embates e disputas características do processo de construção e negociação do campo da memória e do patrimônio.

Cabe ressaltar que existem muitos destes projetos de museus e memoriais, implantados em contextos de justiça de transição, que vão optar pela execução de edifícios de nova arquitetura, em que a linguagem utilizada permite o uso do projeto arquitetônico de maneira a construir um forte simbolismo, com o intuito de causar impacto no público antes mesmo que este adentre o espaço museal. A escolha de materiais e formas perpassa pela mensagem que a instituição deseja comunicar ao público. Pode-se constituir na tentativa de transmitir a experiência da violência do trauma histórico abordado. Assimetrias, distorções, corredores e formas de deslocamento sempre em mutação, vazios, estruturas fragmentadas, rasgos e um sem número de outras estratégias que adentram o repertório arquitetônico de maneira a propor o engajamento do visitante. Como por oposição, a edificação também pode expressar valores e ideias que se relacionam ao trauma através de características antinômicas, esboçando, por exemplo, uma mensagem de paz e tranquilidade, por oposição ao acontecimento de violência e agitação. Superfícies claras, simetria, curvas harmônicas, fontes e espelhos d'água - que aparecem como elemento de 
purificação. Independente da escolha adotada o que parece quase como impossível é uma relação de indiferença com sua intervenção no espaço.

É nesta vertente que se encontra o projeto do Memorial da Liberdade e Democracia Presidente João Goulart. Com concepção arquitetônica de Oscar Niemeyer, a iniciativa do Instituto João Goulart pretende instalar em Brasília um museu dedicado às memórias do período e que, ao mesmo tempo, dialogue com os valores democráticos e o ideal de liberdade no contemporâneo.

Os entraves à implantação do museu passam por questões que vão desde uma contestação do desenho arquitetônico, com a marcação de uma estrutura em forma de seta vermelha com a inscrição do ano de 1964, à escolha do terreno para implantação da iniciativa, próximo ao setor militar urbano, considerados como uma provocação aos setores militares.

Por fim, ressalto que a musealização é apenas uma das formas de preservação associadas à proteção destes lugares e à transmissão destas memórias. Não se advoga aqui um desejo de musealização integral de todos os bens relacionados à memória destes episódios. É necessário que, antes de tudo, uma sociedade saiba fazer a correta gestão de seus bens patrimoniais, dando voz aos diferentes grupos envolvidos e ponderando a "adequada" aplicação de diferentes instrumentos de preservação. O desenvolvimento de políticas da memória deve levar em conta a dinâmica de mudança e renovação presente nos espaços urbanos.

\section{Considerações finais}

$\mathrm{Na}$ atualidade, os museus e demais instituições de memória começam a abarcar uma temporalidade que é cada vez mais expandida e têm de lidar com uma diversidade de memórias e narrativas sem precedentes. Dentre elas, a consagração de toda uma série de patrimônios relacionados às memórias de catástrofes, guerras, genocídios, episódios de opressão, contextos de escravidão, tortura, sofrimentos, e toda sorte de situações traumáticas que, a partir das reivindicações de diferentes grupos, assumem um valor simbólico e memorial.

Uma vez que a memória se enraíza no concreto, no espaço, nos gestos, nas imagens e nos objetos, ao serem transformadas em instituições museais, a 
materialidade destes lugares se torna testemunho que permite aos diferentes grupos sociais envolvidos mobilizar estas memórias, geralmente legadas ao esquecimento. Inserido-as em uma experiência compartilhada de identificação com os diferentes grupos e suas memórias.

Neste sentido, a invisibilidade e o silêncio constituem dois fatores fundamentais para a continuidade das violações dos direitos humanos e da impunidade. A construção de uma memória pública sobre estes acontecimentos, aqui considerada sob a forma dos museus, permitiria uma quebra do silêncio, ao mesmo tempo em que apresenta o potencial de dar voz e rosto às vitimas, configurando-se como poderosas ferramentas no combate às violações de direitos humanos.

No entanto, estas experiências nos permitem questionar até que ponto o aporte de recursos a estas instituições não é dependente de uma autorização do discurso institucional. Certos temas, principalmente ligados às memórias traumáticas, podem ser incômodos na promoção de uma paz ou coesão social, podendo afetar inclusive a imagem dos governos de um país no exterior.

Ao longo do ensaio, foram apresentados alguns dos possíveis enquadramentos e narrativas dos projetos e das instituições museais identificadas. No entanto, pretende-se efetivar essa análise de maneira aprofundada por meio do desenvolvimento da tese de doutorado ora em curso, retomando aspectos fundamentais da bibliografia analisada.

Os processos e as iniciativas de memorialização se tornam, portanto, em contextos de justiça de transição, um desafio intelectual, ético e político. Por sua própria natureza, a justiça transicional deve ser um processo transitório, o que coloca o estabelecimento de instituições de memória como um instrumento chave na construção de mecanismos que atuem no longo prazo.

Dentre as chamadas instituições de memória e informação, os museus têm um papel seminal na sociedade contemporânea como mediadores entre o público e seu acervo, aqui inclusas as memórias das quais estes se tornam guardiões. Estas instituições operam a um só tempo como campos discursivos, centros de interpretação e arenas públicas. Neste sentido, a relação entre museu, comunicação e informação demonstra-se estreita, tendo em vista que a maneira 
pela qual o público recebe e ressignifica as mensagens de suas exposições é que garante e assegura a legitimidade da função social do museu.

Como campo fundamentalmente interdisciplinar, a Ciência da Informação aproxima-se da museologia apresentando vários pontos de contato. Seja em abordagens que tratam o museu como centro de documentação, como espaço de informação e interatividade, ou ainda, através do uso crescente de tecnologias da informação nas instituições museais. O conceito de informação torna-se essencialmente um ponto de contato, na medida em que ambas voltamse não mais para os produtos (os artefatos em suas mais diversas configurações), mas sim para as ações e interações humanas.

Os museus que lidam com memórias do trauma apresentam uma vontade de conexão do passado ao presente, da memória à ação. Várias questões éticas devem ser consideradas para que a instância de engajamento que propõem não se converta na opressão do outro, o que poderia resultar numa situação de injustiça social. Ao omitir, segregar ou se distanciar dos grupos sociais, sejam eles portadores das memórias que trabalham ou herdeiros desta memória compartilhada, o museu pode acabar servindo mais ao esquecimento do que à lembrança. Faz-se necessário observar uma postura crítica para que essas instituições, ao se utilizarem de diferentes suportes de informação para lidar com as questões da memória do trauma, ao se converterem em lugar de memória, não se constituam em locais de amnésia.

\section{Referências}

ABRÃO, Paulo. Direito à verdade e à justiça na transição política brasileira. In: ABRÃO, Paulo; GENRO, Tarso. Os direitos da transição e a democracia no Brasil: Estudos sobre justiça de transição e teoria da democracia. Belo Horizonte: Fórum, 2012. cap. 4, p. 59-80.

ABRÃO, Paulo; DIÈNE, Doudou. Préfácio. In: GABRIEL, Bix (ed.). Fortalecimento da memória, da justiça e dos direitos humanos no Brasil e no Hemisfério Sul. Brasília: Comissão Brasileira de Anistia, 2015. p. 11-16.

ABRÃO, Paulo; GENRO, Tarso. Os direitos da transição e a democracia no Brasil: estudos sobre justiça de transição e teoria da democracia. Belo Horizonte: Fórum, 2012. 
BAUER, Caroline Silveira. O lugar da história e da memória em uma avenida: embates pela mudança da Avenida Castelo Branco (Porto Alegre, 2011-2014). In: SEMINÁRIO INTERNACIONAL DE MEMÓRIA E PATRIMÔNIO, 8., 2014, Pelotas. Anais [...]. Pelotas: UFPel, 2014. p. 338-344.

BRASIL. Lei $n^{\circ} 6.683$, de 28 de agosto de 1979. Concede anistia e dá outras providências. Presidência da República. Brasília, 28 ago. 1979.

BRASIL. Lei $n^{\circ} 12.528$, de 18 de novembro de 2011. Cria a Comissão Nacional da Verdade no âmbito da Casa Civil da Presidência da República. Casa Civil: Subchefia para Assuntos Jurídicos. Brasília, 18 nov. 2011. Lei ordinária.

\section{BRASIL. COMISSÃO NACIONAL DA VERDADE. Relatório da Comissão} Nacional da Verdade. Brasília: CNV, 2014. v. 1.

CARVALHO, Claudia Paiva; GUIMARÃENS, José. Otávio. Nogueira.; GUERRA, Maria Pia (Org.). Justiça de transição na América Latina: panorama 2015. Brasília: Ministério da Justiça, 2016. Edição bilíngue, em espanhol: Justicia de transición en América Latina: panorama 2015.

CASTRO, Ana Lúcia Siaines de. Memórias clandestinas e sua museificação: uma prospecção sobre institucionalização e agregação informacional. 2002. Tese (Doutorado em Ciência da informação) - Escola de Comunicação, Universidade Federal do Rio de Janeiro, Rio de Janeiro, 2002.

FERRAZ, Joana D`arc Fernandes. Os desafios da preservação da memória da ditadura no Brasil. In: ABREU, Regina; CHAGAS, Mário; SANTOS, Myriam (org.). Museus, coleções e patrimônios: narrativas polifônicas. Rio de Janeiro: Garamond, 2007. p. 48-67.

FROTA, Maria Guiomar da Cunha. Memórias da repressão e da resistência: um olhar comparado entre Brasil e Argentina. Revista Informação na Sociedade Contemporânea, Natal, v. 1, n. 2, p. 1-17, jan./jun. 2017.

HUYSSEN, Andreas. Seduzidos pela memória: arquitetura, monumento, mídia. Rio de Janeiro: Aeroplano, 2000.

HUYSSEN, Andreas. Culturas do passado-presente: modernismos, artes visuais, políticas da memória. Rio de Janeiro: Contraponto, 2014.

JELIN, Elizabeth. Los trabajos de la memoria. Madrid: Siglo veintiuno, 2002.

KREUZ, Débora Strieder. A Ditadura civil-militar brasileira e a necessidade de lugares de memória. In: SEMINÁRIO INTERNACIONAL DE MEMÓRIA E PATRIMÔNIO, 8., 2014, Pelotas. Anais [...]. Pelotas: UFPel, 2014. p. 256-262.

MINAS GERAIS. Lei n. 13.448 de 10 de janeiro de 2000. Cria o Memorial de Direitos Humanos. Assembleia Legislativa de Minas Gerais, Belo Horizonte, 01 de jan. 2000. 
NORA, Pierre. Entre memória e história: a problemática dos lugares. Projeto História, São Paulo, v. 10, p. 7-28, dez. 1993.

PEREIRA, Antony W. Ditadura e repressão: o autoritarismo e o estado de direitos no Brasil, no Chile e na Argentina. São Paulo: Paz e Terra, 2010.

REÁTEGUI, Félix (ed.). Transitional Justice: handbook for Latin America. Brasília: Brazilian Amnesty Commission, 2011.

RICOEUR, Paul. A memória, a história, o esquecimento. Tradução: Alain François. Campinas: Unicamp, 2007.

SOUSA, Prscila Paula de. Memória, objetos e edifícios uma análise arqueológica sobre o edifício que sediou o Deops/SP. Revista de Arqueologia Pública, Campinas, v. 8, n. 2 [10], p. 196-211, dez. 2014.

WINTER, Jay. A geração da memória: reflexões sobre o 'boom da memória' nos estudos contemporâneos de história. In: SELLIGMAN-SILVA, Márcio (Org.). Palavra e imagem: memória e escritura. Chapecó: Argos, 2006. p. 6790 .

\title{
Museums and transitional justice in the Brazilian context: memory and information in the construction of trauma representation spaces
}

\begin{abstract}
Across the globe, events such as the Holocaust, Apartheid, Eleventh of September and the dictatorial periods in Latin America have generated an obligation to be accountable to the past, especially through the necessity of creating places of memory to mark the time. The emergence of museums and memorials about the memories of repression and resistance in the dictatorial contexts of the Latin American countries of the Southern Cone follows this global context in which is observed the creation of a growing number of information and memory institutions that adopt the local causes in relation to human rights as the main issue of their institutional mission. Regarding the Brazilian context, the measures that characterize the field of transitional justice have differentiated stages of implementation in each one of its dimensions and, in general, different authors recognize that many measures are considered late in relation to other Latin American countries. This essay aims to analyze the emergence of museum institutions in contexts of transitional justice focused on the Brazilian reality. Some of the central aspects that involve the establishment of these institutions and some of the issues involved are outlined. Finally, it presents some of these initiatives at the national level.
\end{abstract}

Keywords: Memory. Information. Museum. Transitional Justice. Brazil. 
Recebido: 10/04/2018

Aceito: 02/08/2018

${ }^{1}$ A este respeito ver Reátegui (2011) e Huyssen (2014).

${ }^{2}$ Para exemplificar a violência estatal no contexto ditatorial citam-se parte dos dados sistematizados por Pereira (2010). Os dados estimados em relação à repressão no Brasil entre os anos de 1964 e 1979, no Chile entre 1973 e 1989 e na Argentina de 1976 a 1983 são respectivamente: 284 a $364,3.000$ a 5.000 e 20.000 a 30.000 mortes e desaparecimentos; $25.000,60.000$ e 30.000 presos políticos; e $10.000,40.000$ e 500.000 exilados.

${ }^{3}$ As Comissões da Verdade e Reconciliação são umas das instâncias criadas, geralmente, após o fim de regimes de exceção e tem como finalidade investigar e avaliar as violações aos direitos humanos efetuadas durante estes regimes e, a partir de suas conclusões, decidir como reparálas. A experiência mais conhecida de Comissão da Verdade é o modelo Sul-africano, criado naquele país para a investigação após o regime do Apartheid. Por sua notoriedade o modelo de Comissão da Verdade adotado na África do Sul foi exportado para outros países do mundo (HUYSSEN, 2014).

${ }^{4}$ No original: La controversia y el conflicto de interpretaciones no se aquietan necesariamente una vez construido el memorial, el museo o el monumento, con la versión del sentido del pasado que quienes lograron su cometido impusieron o negociaron. El paso del tempo histórico, político y cultural necesariamente implica nuevos procesos de significación del pasado, con nuevas interpretaciones. $\mathrm{Y}$ entonces surgen revisiones, cambios en las narrativas y nuevos conflictos [...](JELIN, 2002, p.56-57).

${ }^{5}$ No original: Las transiciones en el Cono Sur fueron distintas y singulares y las memorias de los conflictos sociales previos a la instauración dictatorial, así como la crudeza e inmediatez de las violaciones a los derechos humanos durante las mismas, crearon escenarios para la manifestación de confrontaciones, en el marco de un difícil intento de generar consensos entre los diversos actores políticos. Las voces censuradas y prohibidas comenzaron a hacerse oír, pero las voces autoritarias no necesariamente desaparecieron del debate público. [...] Eran actores y fuerzas políticas internas [...] que tenían que convivir en el marco de nuevas reglas de funcionamiento democrático. (JELIN, 2002, p. 47).

${ }^{6}$ Ao levar em consideração, por exemplo, o caso Argentino em que desde as eleições democráticas de Raúl Alfonsín em dezembro de 1983, já podem ser observadas medidas como o chamado "Julgamento das Juntas", de 1985, no qual foram julgados e condenados integrantes das três primeiras juntas militares: oficiais superiores do Exército, da Marinha e da Aeronáutica ou ainda com a criação, já em 1984, da "Comisión Nacional sobre la Desaparición de Personas" (Conadep), que publicou o relatório Nunca Más. No contexto Chileno já em 1990, mesmo ano do primeiro governo democraticamente eleito pós Pinochet, é criada a Comissão Nacional da Verdade e Reconciliação (Comissão Rettig), sem competências, contudo, para judicializar os crimes que investigou. No Uruguai, com o retorno do governo democrático através das eleições de novembro de 1984, são criadas em 1985 duas comissões para investigar, em caráter oficial, as violações aos direitos praticadas durante a ditadura. Informações mais detalhadas sobre as medidas dos processos de transição, não só nestes países, mas também em outras nações latino-americanas podem ser encontradas em obra editada pela Rede Latino-americana de Justiça de Transição (CARVALHO; GUIMARÃENS; GUERRA, 2016).

${ }^{7}$ A CNV foi criada pela Lei 12.528/2011 e instituída em 16 de maio de 2012. Tem por finalidade apurar graves violações de Direitos Humanos ocorridas no país entre os dias 18 de setembro de 1946 e 5 de outubro de 1988. Seu mandato se estendeu até o mês de dezembro de 2014, com a entrega dos relatórios finais da Comissão. Entre os focos principais da CNV estava à apuração dos casos de desaparecidos políticos, bem como a identificação dos lugares relativos as práticas de opressão do regime ditatorial. 